\title{
Predicting the impacts of climate change on the distribution of Juniperus excelsa M. Bieb. in the central and eastern Alborz Mountains, Iran
}

\author{
Samira Sadat Fatemi ${ }^{(1)}$, \\ Mohammad Rahimi ${ }^{(1)}$, \\ Mostafa Tarkesh ${ }^{(2)}$, \\ Hooman Ravanbakhsh ${ }^{(1)}$
}

\begin{abstract}
In recent years, global climate change has had significant biological, temporal, and spatial effects on many terrestrial habitats. The objective of this study was to evaluate the effect of climate change on the geographic distribution of Juniperus excelsa and prioritize its habitats for protection against these effects until 2070. The study was conducted using the MaxEnt species distribution model and two data series GFDL-CM3 and MRI-CGCM3 under scenarios RCP2.6 and RCP4.5 of the $5^{\text {th }}$ IPCC report. Our results revealed that elevation, minimum temperature of coldest month, precipitation of coldest quarter, annual mean temperature, and slope aspect, in that order, have the greatest effects on the species' distribution in the study area. Under optimistic scenario RCP2.6, both models predicted that the species' presence area will grow, but under RCP4.5, models predicted that by 2070 , some parts of its habitat in western and central heights will be lost because of change in climate parameters like minimum temperature of coldest month and precipitation of coldest quarter. Under the latter scenario, the northeastern parts of the study area showed no changes in terms of climatic parameters and climatic niche. The results of both climate data series indicated that the Juniperus excelsa will slowly migrate to higher elevations to cope with the changing climate. Assessment of the results through field studies showed that outputs of GFDL-CM3 are closer to the reality.
\end{abstract}

Keywords: Juniperus excelsa, Climate Change, Irano-Turanian Forests, MaxEnt Model, Climatic Niche distribution data has simplified the use of Species Distribution Models (SDMs) in ecology research. These models relate the environmental parameters to the presence or absence of plant-animal species by the use of quantitative equations, which are then used to predict the species distribution in unsampled areas, the environmental changes and the resulting ecological conse2010, Guisan \& Zimmermann 2000, Miller \& Rogan 2007). Researchers have developed several SDMs for assessing the response of plant communities (Fischer 1990), forest ecosystems (Brzeziecki et al. 1995) and individual species (Guisan \& Theurillat 2000). SDMs can be classified into two categories: quences (Elith \& Leathwick 2009, Franklin

(1) Faculty of desert studies, Semnan University, Semnan (Iran); (2) Faculty of Natural Resources, Isfahan University of Technology (Iran)

@ Mohammad Rahimi (mrahimi@semnan.ac.ir)

Received: Jul 19, 2017 - Accepted: Jul 22, 2018

Citation: Fatemi SS, Rahimi M, Tarkesh M, Ravanbakhsh H (2018). Predicting the impacts of climate change on the distribution of Juniperus excelsa M. Bieb. in the central and eastern Alborz Mountains, Iran. iForest 11: 643-650. - doi: 10.3832/ifor2559-011 [online 2018-10-04] profile techniques and group discrimination techniques. Profile techniques, like BIOCLIM (Parra et al. 2004), Gower similarity or DOMAIN (Segurado \& Araujo 2004), GARP (Anderson et al. 2003), ecological niche factor analysis or BIOMAPPER (Hirzel et al. 2002) and MAXENT (Phillips et al. 2006) use presence-only records. These methods are used when absence data is unavailable or unreliable. Group discrimination techniques use both present and absence records and are classified into two categories: (i) global models like GLM (Guisan et al. 2002) and local models like MARS (Munoz \& Felicisimo 2004); and (ii) classification techniques, like CART (Segurado \& Araujo 2004) and GAM (Lehmann et al. 2002), which are known as "nonparametric" models (Tarkesh \& Jetschke 2012). There have been numerous studies on the SDMs application to the assessment of plant species response to change in climate parameters. In a study by Khanum et al. (2013), the effect of climate change on three species of medicinal plant Asclepiads in Pakistan was assessed by the MaxEnt model. In this study, three AOGCM models $\mathrm{HadCM}_{3}, \mathrm{CCCMA}$ and CSIRO scenario $\mathrm{A} 2$ were employed to predict the desirable habitat of these three species in 2050. The results of this study proved the good performance of the MaxEnt model in predict- 
ing the distribution of species, especially the rare ones. In a study by Remya et al. (2015), the MaxEnt model was used to predict the proper distribution of Myristica dactyloides species in eastern India; predic tion was made for the years 2050 and 2070 at a scale of $1 \mathrm{~km}$ by two different CMIP5 models GFDL-CM3 and NorESM1-M and with the help of MaxEnt model. The results revealed that variables influencing the species' distribution are air temperature, annual precipitation and precipitation of the wettest month. It was also shown that by 2050 and 2070, the area of species dis tribution will shrink to some extent. The results also demonstrated the good performance of MaxEnt model for predicting climate change-induced habitat alteration and for planning conservation measures. $L$ et al. (2016), studied the geographica boundaries of Pinus tabulaeformis in China using the MaxEnt model under 7 GCM models and four RCP scenarios. Their results revealed that Precipitation of Wettest Month (PWM), Annual Biological Temperature (ABT), Mean Temperature of Coldest Month (MTCM), Annual Mean Temperature (AMT), Precipitation of Driest Month (PDM), Cloudiness index (CL), Annual Precipitation (AP) and Mean Temperature of Warmest Month (MTWM) are the variables with the highest effect on P. tabulaeformis species in the area and explain $94.6 \%$ of changes.

Juniperus excelsa, commonly called Juniper, is one of the valuable tree species living in semi-arid mountains and harsh environments of the Irano-Turanian phytogeographic region (Sagheb-Talebi et al. 2014). The species is also present in eastern Mediterranean, the Balkans, Turkey, and mountains of Iran, Afghanistan and Pakistan. In Iran, Juniper communities are present in the mountainous forests of the central Iranian plateau at the altitude of 1700 to 2800 (3400 in the southern regions) $\mathrm{m}$ a.s.l. (Ravanbakhsh et al. 2013). Zohary (1973) argued that current Juniper communities of Iran are remnants of vast forests formerly covering this region, which have been reduced due to anthropogenic factors, climate conditions and erosion of mountain areas. Among various Juniperus species in Iran, J. excelsa has the highest frequency and is sensitive to environmental changes, especially climatic variations (Pourtahmasi et al. 2008). J. excelsa is also one of the most important forest species in terms of soil conservation (Fallah et al. 2014), as its communities, whether in pure or mixed populations, are located in soils with heavier textures and higher water saturation than other forest communities in the Irano-Turanian region (Ravanbakhsh \& Moshki 2016). According to the IUCN Red List (IUCN 2016), J. excelsa is classified into the category of Least Concern, but Iranian environmental protection organization claims that $J$. excelsa forests are endangered and rapidly shrinking, especially in the southern slopes of the Alborz Mountains. In addition, local residents extract various parts of this plant for economic purposes. Thus, considering the importance of J. excelsa in soil conservation and biodiversity, its future distribution in the Alborz Mountains is worthy of attention. Knowing the future distribution of these species, the preservation measures aimed at preventing further loss of habitat and controlling the risk of desertification can be planned with greater accuracy. The goal of this study was therefore to determine the geographical distribution of J. excelsa in an important part of its habitat in Iran at present and in the future using the results of climate models under forecasted scenarios RCP 2.6 and RCP4.5.

\section{Material and methods}

\section{Study area}

The study area encompasses the southern slopes of the eastern Alborz Mountains (between $35^{\circ} 31^{\prime}-36^{\circ} 52^{\prime} \mathrm{N}$ and $52^{\circ} 31^{\prime}-55^{\circ}$ $26^{\prime} \mathrm{E}$ ) in Semnan and Tehran provinces, located in the center-north parts of Iran, and has an area of $14,656.14 \mathrm{~km}^{2}$ (Fig. 1). The elevation ranges between 996 and $3861 \mathrm{~m}$ a.s.l. and its annual mean temperature varies between 1.1 and $16{ }^{\circ} \mathrm{C}$. In terms of vegetation cover, the study area is located in the Irano-Turanian phytogeography region with tree and shrub species distrib- uted at elevations between 1000 and 3000 $\mathrm{m}$ a.s.l. (Sagheb-Talebi et al. 2014). J. excelsa is present at elevations between 1800 to $2800 \mathrm{~m}$ a.s.l. and Pistacia atlantica and Amygdalus spp. communities can be found at elevations between 1300-1800 m a.s.l. (Ravanbakhsh et al. 2016). According to the De Martonne's aridity index (I), this area falls into the arid and semi-arid class with $5>1>21$. A climatograph of the study area is shown in Fig. S1 (Supplementary material).

\section{Sampling}

First, the population of J. excelsa in the study area was identified by satellite images and field studies; then this population was divided into several homogeneous subpopulations in terms of physiographic factors such as slope, aspect, and altitude. The maps of slope, aspect and altitude were overlaid and maximum effort was made to select at least one presence site in different environmental combinations (homogenous classes resulting from physiographic parameters). For a sufficiently powerful analysis, the ratio of the number of sites to the number of predictor variables should be at least 0.1 , although this value is also affected by the spatial correlation (Miller 2010). Finally, $240 \mathrm{~J}$. excelsa presence sites with spatial scale of 30 arcseconds $(\sim 900 \times 900 \mathrm{~m})$ were selected and used as model input.

\section{Environmental variables}

Nineteen substantial bioclimatic variables for J. excelsa habitat were selected from the WorldClim database (http://www.world clim.org/bioclim - Hijmans et al. 2005). These variables have been derived from monthly temperature and precipitation parameters over the period of 1950-2000 and are closely associated with growth and development of species, thus they are widely used in the assessment of species distribution (Elith et al. 2006, Graham et al. 2008, Warren et al. 2013). To verify the accuracy of acquired data, the variable "Monthly Mean Temperature" was compared with 50-year records from meteorological stations located in the study area. Statistics and information of selected synoptic sta-
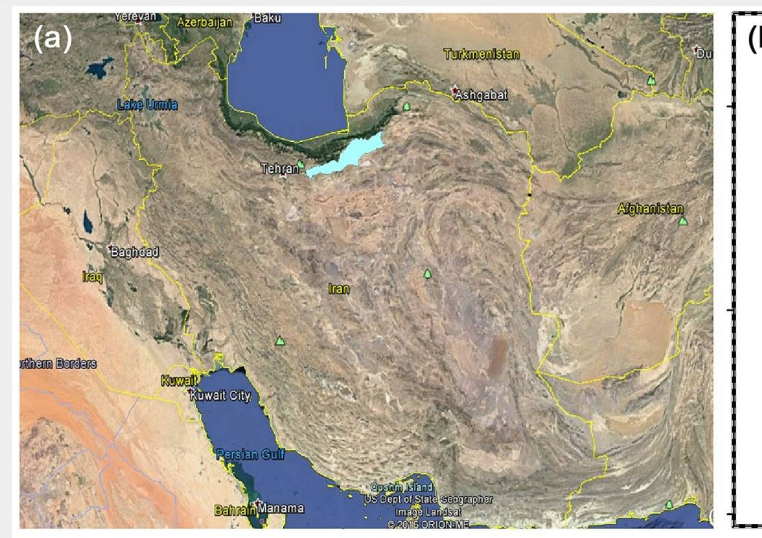

(b)

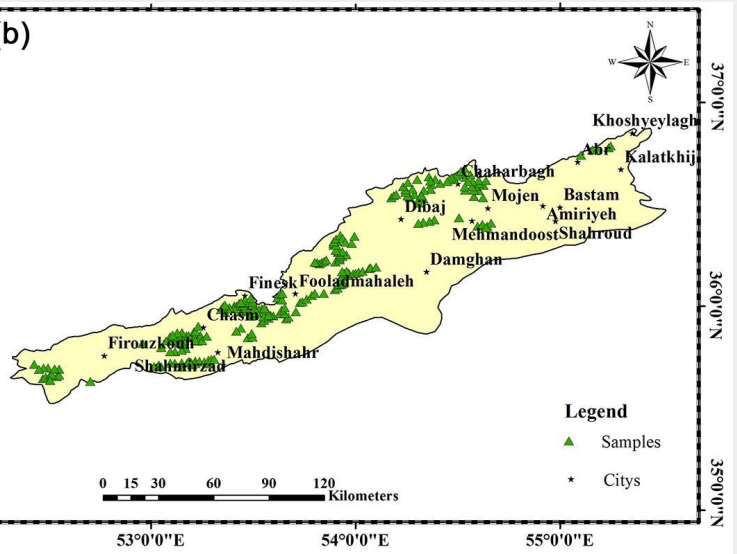

Fig. 1 - (a) Location of the study area (light blue) in Iran. (b) Geographic distribution of sampling sites (green triangles) within the study area. 
tions (4 stations) were collected from Iran Meteorological Organization. Kendall's Tau-b coefficient of correlation between observed data and Worldclim data was calculated. In all stations, the results showed correlations of more than 0.9, which confirmed the suitability of Worldclim data for the present study.

In addition to bioclimatic data, layers such as slope and aspect were produced from a digital elevation model (DEM) with resolution of $90 \mathrm{~m}$. This model was downloaded from the USGS website (https:// www.usgs.gov/) and then resampled by ArcGIS $^{\oplus}$ ver. 10.2 (ESRI, Redlands, CA, USA) to a spatial scale of 30 arc-seconds ( $900 \mathrm{~m}-$ Tab. 1). The model input variables were selected using Pearson's correlation coefficients ( \pm 0.8 - Priti et al. 2016) and PCA (Barbet-Massin et al. 2012) methods according to ecological significance of variables for the species. Pearson's correlation coefficients and PCA were determined by inter-variable analysis with statistical software SPSS ${ }^{\circledast}$ ver. 23 (IBM, Armonk, NY, USA). Climate data to be used for prediction was collected from WorldClim database available from CMIP5 (IPPC Fifth Assessment) for the years 2050 (average of 2041-2060 period) and 2070 (average of 2061-2080 period). This data has been predicted using 19 GCM models under four greenhouse gas concentration scenarios known as Representative Concentration Pathways (RCPs). In this study, the climate models GFDL-CM3 (Geophysical Fluid Dynamics Laboratory version 3) developed by NOAA (National Oceanic and Atmospheric Administration) and MRI-CGCM3 developed by MRI (Meteorological Research Institute) were used under scenarios RCP2.6 and RCP4.5. MRI-CGCM3 is an improved version of MRI-CGCM2 and is composed of atmosphere-land, aerosol, and ocean-ice models and a subset of the MRI's earth system model MRI-ESM1 (Yukimoto et al. 2012). Scenario RCP 2.6 represents an optimistic conditions with peak radiative forcing of about $3 \mathrm{w} \mathrm{m}^{-2}\left(\sim 490 \mathrm{ppm} \mathrm{CO} \mathrm{CO}_{2}\right.$-eq) before 2100 followed by a decline to $2.6 \mathrm{~W}$ $\mathrm{m}^{-2}$. Scenario RCP 4.5 represents a more moderate projection with stabilization of radiative forcing at $4.5 \mathrm{~W} \mathrm{~m}^{-2}(\sim 650 \mathrm{ppm}$ $\mathrm{CO}_{2}$-eq) by 2100 (Yukimoto et al. 2012).

\section{MaxEnt model}

MaxEnt (Phillips et al. 2006) is a machinelearning model for predicting the species' potential distribution using the environmental information and the species' presence data (Elith et al. 2011). This model can use both continuous and categorical data and can incorporate interactions between different variables (Phillips et al. 2006). Studies have shown that MaxEnt can well compete with highly accurate prediction methods, even when sample size is small (Anderson \& Gonzalez 2011). This model was run for the present and future (20502070) distributions. When constructing the model, $75 \%$ of data (selected at random)

Tab. 1 - Input variables for the MaxEnt model and the percentage contribution (\%) and permutation importance $(\%)$ of each variable. $(*)$ : Variables selected after Pearson's correlation analysis and used in modeling; (CV): coefficient of variation.

\begin{tabular}{|c|c|c|c|c|c|}
\hline No & Code & $\begin{array}{l}\text { Environmental } \\
\text { variables }\end{array}$ & Unit & $\begin{array}{c}\text { Percentage } \\
\text { contribution } \\
\text { (\%) }\end{array}$ & $\begin{array}{c}\text { Permutation } \\
\text { importance } \\
\text { (\%) }\end{array}$ \\
\hline 1 & Bio1* $^{*}$ & Annual mean temperature & ${ }^{\circ} \mathrm{C}$ & 6.7 & 3.5 \\
\hline 2 & Bio2 & $\begin{array}{l}\text { Mean diurnal range (mean of monthly } \\
\text { max and min temperature) }\end{array}$ & ${ }^{\circ} \mathrm{C}$ & - & - \\
\hline 3 & Bio3* & Isothermality $([\mathrm{Bio} 2 / \mathrm{Bio} 7] \times 100)$ & - & 1 & 1.3 \\
\hline 4 & Bio4 & $\begin{array}{l}\text { Temperature seasonality (standard } \\
\text { deviation } \times 100 \text { ) }\end{array}$ & CV & - & - \\
\hline 5 & Bio5* & $\begin{array}{l}\text { Maximum temperature of warmest } \\
\text { month }\end{array}$ & ${ }^{\circ} \mathrm{C}$ & 0.9 & 0.1 \\
\hline 6 & Bio6* & Minimum temperature of coldest month & ${ }^{\circ} \mathrm{C}$ & 26.9 & 0.6 \\
\hline 7 & Bio7 & Temperature annual range (Bio5-Bio6) & ${ }^{\circ} \mathrm{C}$ & - & - \\
\hline 8 & Bio8* & Mean temperature of wettest quarter & ${ }^{\circ} \mathrm{C}$ & 1.7 & 5 \\
\hline 9 & Bio9 & Mean temperature of driest quarter & ${ }^{\circ} \mathrm{C}$ & - & - \\
\hline 10 & Bio10 & Mean temperature of warmest quarter & ${ }^{\circ} \mathrm{C}$ & - & - \\
\hline 11 & Bio11 & Mean temperature of coldest quarter & ${ }^{\circ} \mathrm{C}$ & - & - \\
\hline 12 & Bio12* & Annual precipitation & $\mathrm{mm}$ & 3.4 & 3.6 \\
\hline 13 & Bio13* & Precipitation of wettest period & $\mathrm{mm}$ & 0.1 & 1 \\
\hline 14 & Bio14 & Precipitation of driest period & $\mathrm{mm}$ & - & - \\
\hline 15 & Bio15* & Precipitation seasonality (CV) & CV & 1.1 & 2.4 \\
\hline 16 & Bio16 & Precipitation of wettest quarter & $\mathrm{mm}$ & - & - \\
\hline 17 & Bio17 & Precipitation of driest quarter & $\mathrm{mm}$ & - & - \\
\hline 18 & Bio18* & Precipitation of warmest quarter & $\mathrm{mm}$ & 0.7 & 8.2 \\
\hline 19 & Bio19* & Precipitation of coldest quarter & $\mathrm{mm}$ & 15.9 & 16.5 \\
\hline 20 & $\mathrm{DEM}^{*}$ & Elevation & $\mathrm{m}$ & 35.2 & 54.2 \\
\hline 21 & Aspect* & Geographic aspects ( 9 categories) & - & 1.7 & 0.6 \\
\hline 22 & Slop & Slope & $\%$ & 4.8 & 3 \\
\hline
\end{tabular}

was used for training and the remaining $25 \%$ was used as test data; the maximum number of background points was set to 10,000 , the number of iterations was set to 15 , and the remaining settings were left at their default values (Yang et al. 2013). MaxEnt model was evaluated by using the area under the receiver operating characteristic (ROC) curve (AUC), True Skill Statistic (TSS) test and Kappa test (Allouche et al. 2006). While generating response curves, the MaxEnt model estimates the relative effect of each predictor (Khanum et al. 2013). Species' presence potential was classified using the four probability classes defined by Yang et al. (2013): least potential $(<0.2)$, moderate potential (0.2-0.4), good potential (0.4-0.6) and high potential (>0.6).

\section{Results}

\section{Current distribution of Juniperus \\ excelsa}

According to the results obtained from the model (Tab. 1), about $90 \%$ of the current distribution of the species was explained by 5 variables: (i) elevation (35.2\%); (ii) minimum temperature of coldest month (26.9\%); (iii) precipitation of coldest quarter (15.9\%); (iv) annual mean temperatures (6.7\%); and (v) slope (4.8\%). The species' response curves for these 5 variables are plotted in Fig. S2 (Supplementary material). The evaluation results $\left(A \cup C_{\text {mean }}=\right.$ 0.948 , TSS $=0.781$ and Kappa $=0.402$ ) indicate the excellent, very good and moderate performance of MaxEnt model in estimating the distribution of $\mathrm{J}$. excelsa, respectively. According to the map of species' presence potential (Fig. 2), $963.33 \mathrm{~km}^{2}$ of the study area have a low potential, $199.67 \mathrm{~km}^{2}$ have a moderate potential, $206.63 \mathrm{~km}^{2}$ have a good potential, and $95.99 \mathrm{~km}^{2}$ have a high potential in this respect.

\section{Future distribution of Juniperus excelsa} by GFDL-CM3 Model

The distribution pattern in the years 2050 (average of 2041-2060 period) and 2070 (average of 2061-2080 period) was estimated using the GFDL-CM3 and scenarios RCP2.6 and RCP4.5. The results showed that under the optimistic scenario RCP2.6, a broader distribution of $\mathrm{J}$. excelsa is predicted by the years 2050 and 2070, particularly in high potential class, for which the area will be $937.17 \mathrm{~km}^{2}$ (or $6.4 \%$ higher than the current area - Fig. 3). The results of GFDL-CM3 under RCP4.5 scenario predicted a decrease in the species' distribution area, particularly in the western and northern parts of the study area (eastern Tehran and northern Semnan, respectively), and that by 2070 , distribution of J. excelsa will be limited to eastern Alborz 


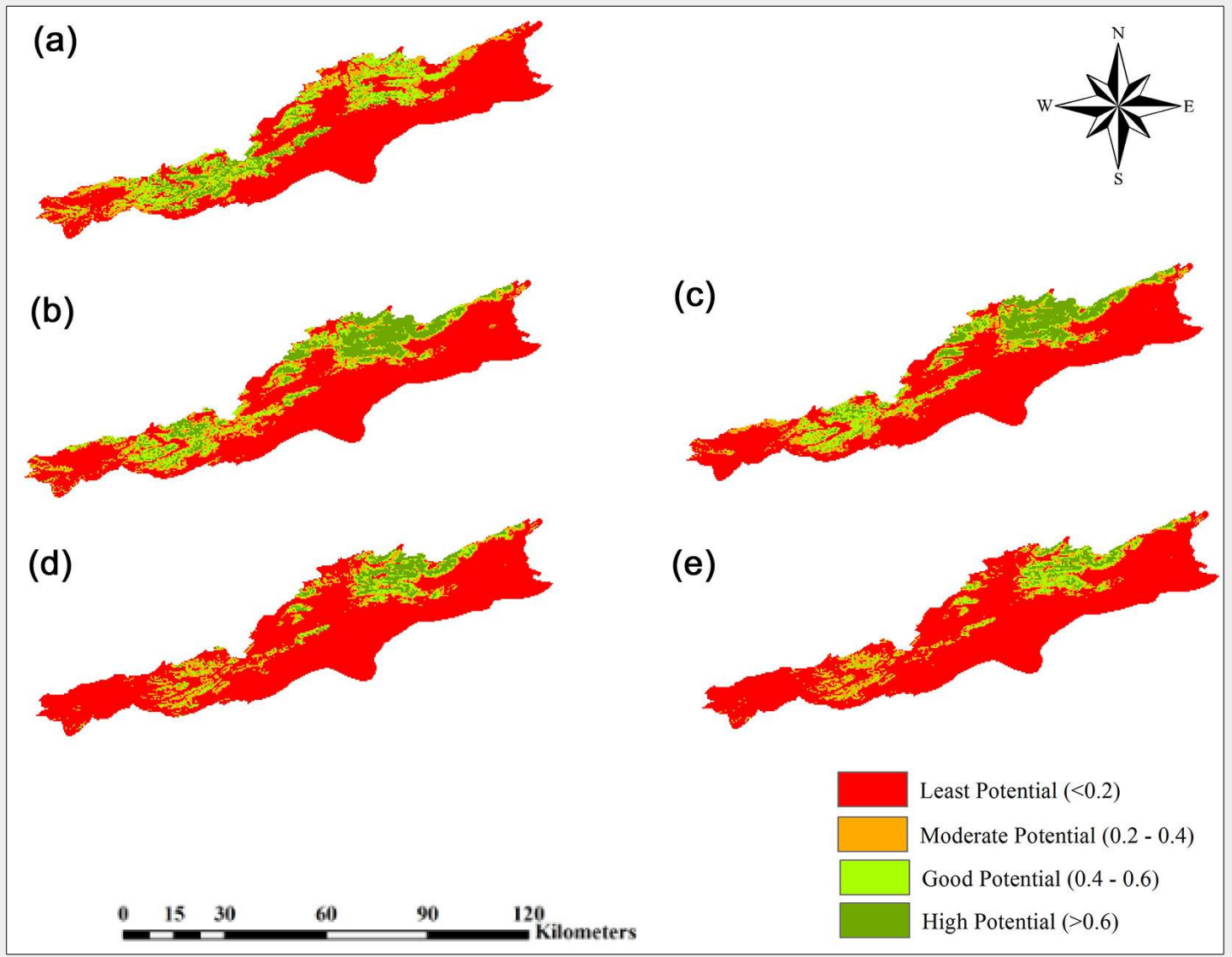

Fig. 2 - Distribution of Juniperus excelsa by GFDL-CM3 Model. (a): Current potential distribution of Juniperus excelsa; (b): future potential distribution in 2050 under $\mathrm{RCP} 2.6$; (c): future potential distribution in 2070 under RCP2.6, (d): future potential distribution in 2050 under RCP 4.5; (e): future potential distribution in 2070 under $\mathrm{RCP} 4.5$.

(northeastern Semnan - Fig. 2). Fig. 3 Future distribution of Juniperus excelsa shows an increase by more than $15 \%$ by MRI-CGCM3 model

$\left(2229.12 \mathrm{~km}^{2}\right)$ in areas with low species presence potential, which means that climate change effects will lead to the replacement of currently suitable habitats with low potential ones. According to the results, by 2070 the current area of good potential habitats will be reduced by $8 \%$ $\left(1185.03 \mathrm{~km}^{2}\right)$ and that of high potential habitats will be reduced by $3 \%\left(494.1 \mathrm{~km}^{2}\right)$.
Unlike GFDL-CM3, MRI-CGCM3 model under RCP2.6 did not show an increase in the species' distribution area (Fig. 4), except for a very slight increase in high-potential class in 2050; in other words, according to this model, both RCP2.6 and RCP4.5 will lead to loss of habitat by 2070 . As shown in Fig. 3, this model predicts that by 2070, the area of low-potential class will increase by
$1.2 \%\left(1768.23 \mathrm{~km}^{2}\right)$ and the areas of goodpotential and high-potential classes will decrease by $6.8 \%\left(997.92 \mathrm{~km}^{2}\right)$ and $0.5 \%(82.62$ $\mathrm{km}^{2}$ ), respectively. The results of this model under RCP4.5 predicted that by 2050 there will be little change as compared with the current distribution, except for a slight decrease in the area of high-potential class. Contrastingly, in 2070 the loss of habitat will be significant and amount to $11.5 \%\left(1697.76 \mathrm{~km}^{2}\right)$ and $6.8 \%\left(950.13 \mathrm{~km}^{2}\right)$ a)

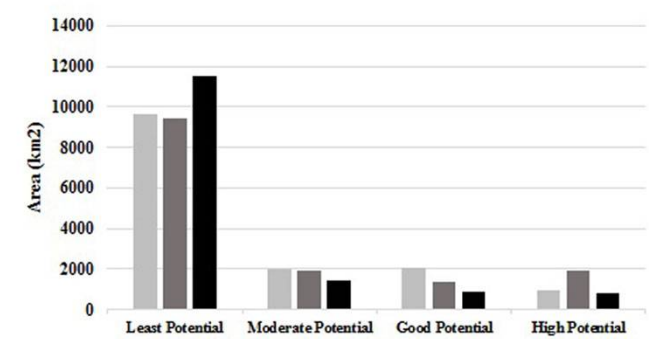

c)

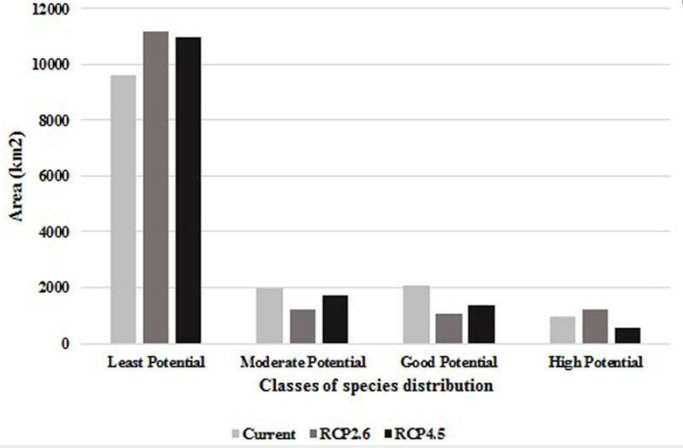

b) 14000

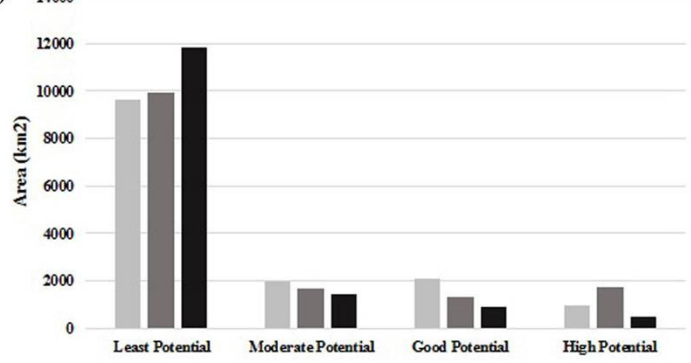

d)

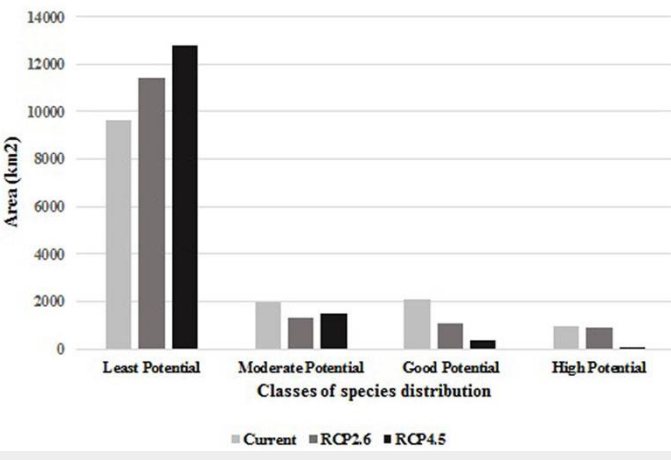

Fig. 3 - Comparison of Juniperus excelsa distribution in current and future situations. (a): Under GFDL-CM3 data in 2050; (b): under GFDL-CM3 data in 2070; (c): under MRI-CGCM3 data in 2050; (d): under MRI-CGCM3 in 2070. 
Fig. 4 - Future potential distribution of Juniperus excelsa predicted by the MRI-CGCM3 model. (a): In 2050 under RCP2.6; (b): in 2070 under RCP2.6; (c): in 2050 under RCP4.5; (d): in 2070 under RCP4.5.

(c)
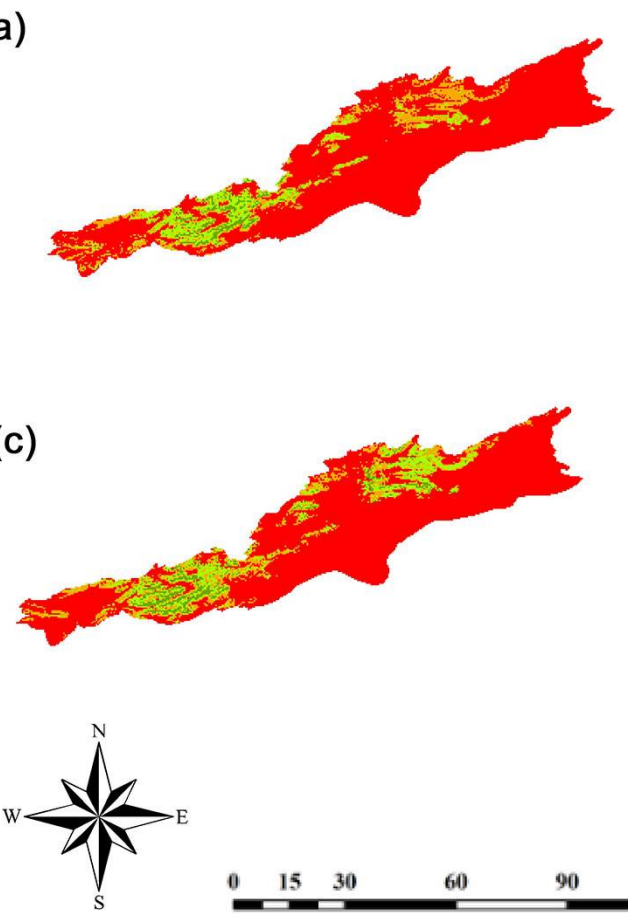

(b)

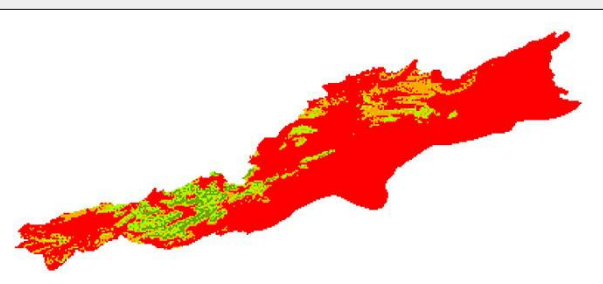

(d)

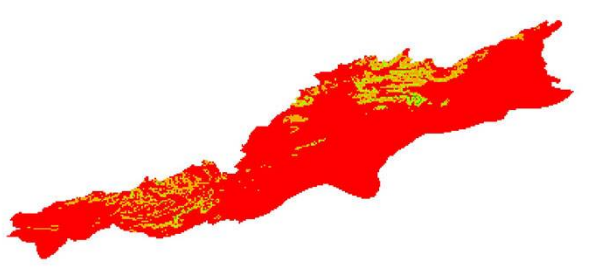

Legend

Least Potential $(<0.2)$

Moderate Potential (0.2 - 0.4)

Good Potential (0.4 - 0.6)

High Potential $(>0.6)$ for good-potential and high-potential areas, respectively. In other words, increased concentration of greenhouse gases will severely reduce the species' presence in the west and center of the study area and will limit its habitats to the northeastern heights. In Fig. 5, the area (in kilometers) of species' presence in the six elevation classes for current and future conditions under RCP2.6 and RCP4.5 are compared. According to the species' response curve and Fig. 5 , the species is currently present at elevations between $1800-3000 \mathrm{~m}$ a.s.l., but the GFDL-CM3 results showed that by 2050 and 2070, the species' presence in elevations $>3500 \mathrm{~m}$ a.s.l. will increase by 2.72 and $3.08 \mathrm{~km}^{2}$, respectively, under scenario $\mathrm{RCP} 2.6$ and 0.81 and $2.1 \mathrm{~km}^{2}$ under scenario
RCP4.5. Also, according to GFDL-CM3, by 2070 the species' presence area at elevations between $3000-3500 \mathrm{~m}$ a.s.l. will show a $30 \mathrm{~km}^{2}$ increase under RCP2.6 or $23 \mathrm{~km}^{2}$ increase under RCP4.5. Thus, GFDL-CM3 predicted that $J$. excelsa will migrate to higher elevations to adapt to changing climate. The results of MRI-CGCM3 under RCP2.6, however, predicted that in 2070 there will be no $J$. excelsa at elevations lower than 1500 and higher than $3500 \mathrm{~m}$ a.s.l., and its presence area in the elevation range $3000-3500 \mathrm{~m}$ will be $10.04 \mathrm{~km}^{2}$ by 2050 , and will slightly decrease $\left(2.51 \mathrm{~km}^{2}\right)$ by 2070 . Under RCP4.5, the MRI-CGCM3 model predicted that the presence area of $\mathrm{J}$. excelsa in the elevation range 3000-3500 $\mathrm{m}$ a.s.l. will be $9.96 \mathrm{~km}^{2}$ by 2050 , and will decrease by $4.94 \mathrm{~km}^{2}$ by 2070 . Thus, the results of both climate data series indicated that the species will slowly migrate to higher elevations to cope with the changing climate.

\section{Discussion}

The results of this study revealed the presence of J. excelsa to be currently limited to the elevation range of $1800-3000 \mathrm{~m}$ a.s.l. with a peak presence at elevations of 2100 to $2800 \mathrm{~m}$; the species was observed on slopes of all aspects but more noticeably in those facing south, east, and southeast; and its presence was found to increase in slopes of 12 to $40 \%$, decrease in slopes of 40 to $60 \%$, and again increase in slopes of 60 to $70 \%$ (Fig. S2 in Supplemen-
Fig. 5 -Comparison a) of Juniperus excelsa current and predicted distributions by elevation category. (a): GFDL-CM3 data under RCP2.6; (b): GFDL-CM3 data under RCP4.5; (c): MRI-CGCM3 data under RCP2.6; (d): MRI-CGCM3 data under RCP4.5.

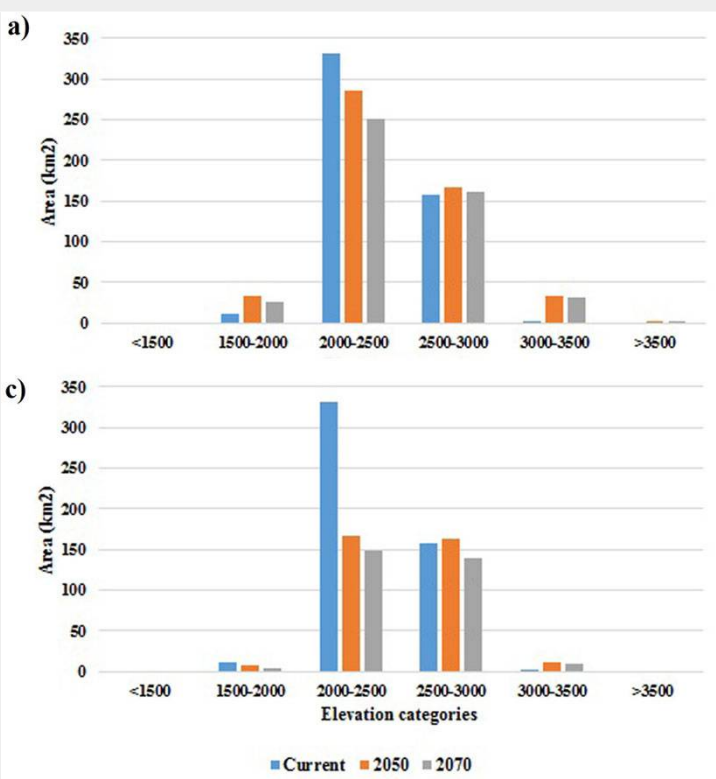

b)

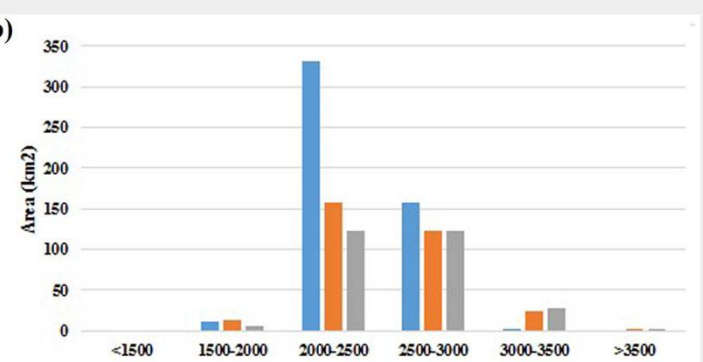

d)

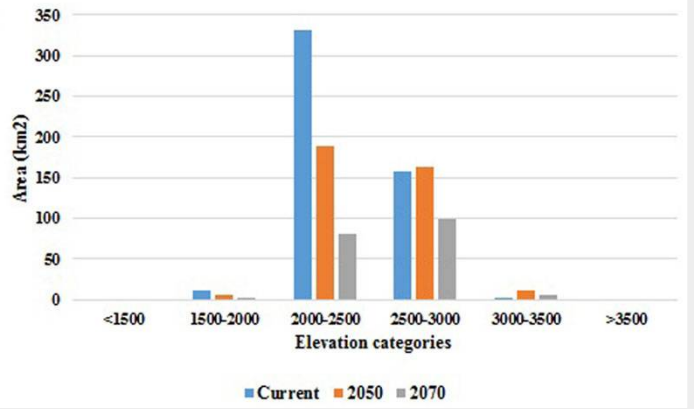


tary material), which are consistent with the findings of a study by Ravanbakhsh \& Moshki (2016) on forests of south central Alborz. The study of Sarangzai et al. (2012) on the ecology and dynamics of J. excelsa in Pakistan have also reported this species to be present at elevations of $2000-3000 \mathrm{~m}$ a.s.l. and slopes of 10 to $30 \%$. Our results showed that the most important factors affecting the species' distribution are elevation, minimum temperature of the coldest month (Bio6 $-4-13{ }^{\circ} \mathrm{C}$ ), and precipitation of coldest quarter (Bio12 - 40-60 mm) in that order. The results indicated that snowmelt in the snow-prone slopes and the resulting water is the most important parameter influencing the growth and distribution of $J$. excelsa in the study region, as the recurrence of three to five-month long dry periods makes the gradual snowmelt a primary source of water. Thus, the species' presence increases with elevation and the persistence of snow cover, due to lower temperatures especially in the cold seasons. Frey \& Probst (1986) described the climate habitat of $J$. excelsa as harsh winter with frost condition $\left(-25^{\circ} \mathrm{C}\right)$ without temperature reduction in summer. The annual mean temperature (Bio1) was found to be the next most important factor affecting the species' distribution. The species was mostly present in areas with annual mean temperature of $7-12{ }^{\circ} \mathrm{C}$, but it was also observed where minimum and maximum temperature are -14.4 and 34.5 ${ }^{\circ} \mathrm{C}$, respectively. However, studies conducted in other parts of the world indicate different temperatures for the presence of J. excelsa. For instance, Hall (1984) reported that areas with annual mean temperatures of less than $19{ }^{\circ} \mathrm{C}$ are most suit- able for this species in Africa, and the treering analysis of J. excelsa by Sass-Klaassen et al. (2007) distinguished the most suitable habitat in northern Oman with mean, maximum, and minimum temperature of $18,36.3$ and $-3.6^{\circ} \mathrm{C}$, respectively.

The results obtained from the GFDL-CM3 model revealed that under scenario $\mathrm{RCP} 2.6$, the desirable habitat of J. excelsa in the study area will grow by 2070. Meanwhile, the corresponding climatic parameters show a $3^{\circ} \mathrm{C}$ increase in mean temperature by that year, suggesting that elevations higher than the current timber line will gradually become more suitable for $J$. excelsa. Also, being resilient and drought resistant, J. excelsa can outperform weaker species that will be further damaged by the temperature rise. However, under scenario RCP 4.5, the results of both GFDL-CM3 and MRI-CGCM 3 models were worrisome, as a significant shrinkage of suitable habitats of J. excelsa, especially those with good and high potential (western and central heights) are forecasted by 2070. Under this scenario, the northeastern area (near Shahrood) is the only zone that will retain favorable growing conditions for the species. Overall, the high-potential habitat of J. excelsa increased by $62.37 \mathrm{~km}^{2}$ under RCP2.6 and decreased by $864.85 \mathrm{~km}^{2}$ under $\mathrm{RCP} 4.5$, mostly due to changes in the western and central parts of the study area. Considering the roles of minimum temperature of the coldest month (Bio6) and the precipitation of coldest quarter (Bio12) as the most important variables influencing the species' distribution under climate change, their mutual effects in determination of climatic niche and ecological response of J. excelsa in both models and un- der both scenarios were analyzed (Fig. S3 in Supplementary material). The results showed that with GFDL-CM3 under RCP2.6, by $2070 \mathrm{~J}$. excelsa is predicted to slightly enlarge its distribution range in the study area. However, under RCP4.5, the curve is skewed to the right, meaning that by 2070 , the annual minimum temperature will rise to $-4{ }^{\circ} \mathrm{C}$ and there will be a change in the climate niche. The results of MRI-CGCM3 un der scenario RCP2.6 showed that by 2050 , there will be a slight increase in precipitation of coldest month and then by 2070 , the minimum temperature of coldest month increases and climatic niche moves further to the right side. The same trend also occurs under RCP4.5 with the rise of minimum temperature to $-2{ }^{\circ} \mathrm{C}$ by 2050 and 2070.

It can be concluded that the likely cause of loss of favorable habitat in the study area will be the change in temperature (mean value or monthly minimum). To check the accuracy of results, 20 sites in the north, east, west and center of study area were randomly selected and compared in terms of annual mean temperature (Bio1, an important factor of the species' distribution in the model) in three periods: present, 2050 and 2070 . The results of both GFDL-CM3 and MRI-CGCM3 showed the rise of annual mean temperature in the western and central regions from 8 to about $16{ }^{\circ} \mathrm{C}$ while up to $12{ }^{\circ} \mathrm{C}$ in the north eastern areas, which is the average ideal value for the presence of $J$. excelsa in the study area. Thus, the effects of climate change on the central and western parts will lead to a faster loss of favorable habitat of J. excelsa. Tab. 2 illustrates the present and future changes in climate pa-

Tab. 2 - Bioclimatic profile of Juniperus excelsa based on its occurrence data.

\begin{tabular}{|c|c|c|c|c|c|c|c|c|c|c|c|c|c|c|c|}
\hline \multirow{3}{*}{ Environmental variables } & \multirow{2}{*}{\multicolumn{3}{|c|}{$\begin{array}{l}\text { Current } \\
\text { Potential }\end{array}$}} & \multicolumn{6}{|c|}{ GFDL-CM3 } & \multicolumn{6}{|c|}{ MRI-CGCM3 } \\
\hline & & & & \multicolumn{3}{|c|}{ RCP2.6 } & \multicolumn{3}{|c|}{ RCP4.5 } & \multicolumn{3}{|c|}{ RCP2.6 } & \multicolumn{3}{|c|}{ RCP4.5 } \\
\hline & Min & Max & Mean & Min & Max & Mean & Min & Max & Mean & Min & Max & Mean & Min & Max & Mean \\
\hline Annual mean temperature & 5.6 & 13 & 9.7 & 8.8 & 15.9 & 12.4 & 9.7 & 16.8 & 13.3 & 7.4 & 14.5 & 10.9 & 7.7 & 15.3 & 11.8 \\
\hline $\begin{array}{l}\text { Mean diurnal range (mean of } \\
\text { monthly max and min temp.) }\end{array}$ & 12.9 & 14.9 & 14.1 & 14 & 16.3 & 15.4 & 14 & 16.4 & 15.3 & 12.7 & 14.4 & 13.7 & 12.9 & 14.4 & 13.8 \\
\hline Isothermality $([\mathrm{Bio} 2 / \mathrm{Bio} 7] \times 100)$ & 34 & 35 & 34 & 34 & 35 & 35 & 33 & 34 & 33 & 32 & 35 & 34 & 32 & 35 & 34 \\
\hline Temp. seasonality (st.dev. $\times 100$ ) & 8643 & 9596 & 9266 & 9292 & 10209 & 9898 & 9883 & 10782 & 10489 & 8629 & 9705 & 9329 & 8773 & 9833 & 9469 \\
\hline Max temp. of warmest month & 27.2 & 34.5 & 30.7 & 32.2 & 39.2 & 35.4 & 33.7 & 40.3 & 36.6 & 29 & 35.8 & 32.4 & 28.6 & 36 & 32.1 \\
\hline Min temp. of coldest month & -14.4 & -6.1 & -9.9 & -13 & -4.5 & -8.4 & -13.4 & -4.9 & -8.8 & -12.4 & -3.9 & -7.9 & -12.9 & -4.3 & -8.3 \\
\hline Temp. annual range (Bio5-Bio6) & 36.9 & 42.8 & 40.6 & 40.3 & 46.4 & 43.8 & 41.9 & 47.9 & 45.4 & 36.4 & 42.3 & 40 & 37 & 42.5 & 40.4 \\
\hline Mean temp. of wettest quarter & 5.1 & 12.2 & 9.3 & 8.3 & 15.2 & 12.1 & 2.6 & 16.1 & 12.6 & 6.2 & 13.5 & 10.6 & -0.8 & 13.7 & 8.7 \\
\hline Mean temp. of driest quarter & 12.2 & 23.7 & 20.2 & 16.7 & 27.8 & 24 & 177 & 293 & 248 & 14.3 & 25.5 & 21.5 & - & - & - \\
\hline Mean temp. of warmest quarter & 17.4 & 24.7 & 21.3 & 21.5 & 28.3 & 24.8 & 23.2 & 29.9 & 26.5 & 19.2 & 26.4 & 22.6 & 19.3 & 26.9 & 23.3 \\
\hline Mean temp. of coldest quarter & -6.9 & 1 & -2.6 & -4.5 & 3.3 & -0.5 & -4.5 & 3.2 & -0.5 & -5.5 & 2.2 & -1.5 & -5.1 & 2.7 & -0.81 \\
\hline Annual precipitation & 128 & 188 & 154 & 135 & 193 & 162 & 132 & 183 & 153 & 134 & 205 & 165 & 138 & 200 & 161 \\
\hline Precipitation of wettest period & 22 & 37 & 29 & 27 & 44 & 35 & 22 & 40 & 31 & 26 & 41 & 32 & 24 & 36 & 28 \\
\hline Precipitation of driest period & 0 & 4 & 1 & 0 & 3 & 1 & 0 & 3 & 1 & 0 & 4 & 2 & 0 & 4 & 1 \\
\hline Precipitation seasonality $(\mathrm{CV})$ & 60 & 82 & 72 & 64 & 89 & 78 & 64 & 91 & 80 & 56 & 85 & 73 & 58 & 81 & 69 \\
\hline Precipitation of wettest quarter & 60 & 101 & 80 & 69 & 111 & 89 & 65 & 103 & 83 & 65 & 107 & 84 & 67 & 102 & 78 \\
\hline Precipitation of driest quarter & 3 & 13 & 8 & 3 & 11 & 7 & 2 & 11 & 6 & 3 & 15 & 8 & 3 & 13 & 8 \\
\hline Precipitation of warmest quarter & 6 & 20 & 12 & 7 & 20 & 13 & 5 & 17 & 10 & 6 & 22 & 13 & 5 & 20 & 12 \\
\hline Precipitation of coldest quarter & 43 & 57 & 47 & 42 & 55 & 46 & 45 & 60 & 50 & 45 & 63 & 51 & 51 & 66 & 56 \\
\hline
\end{tabular}




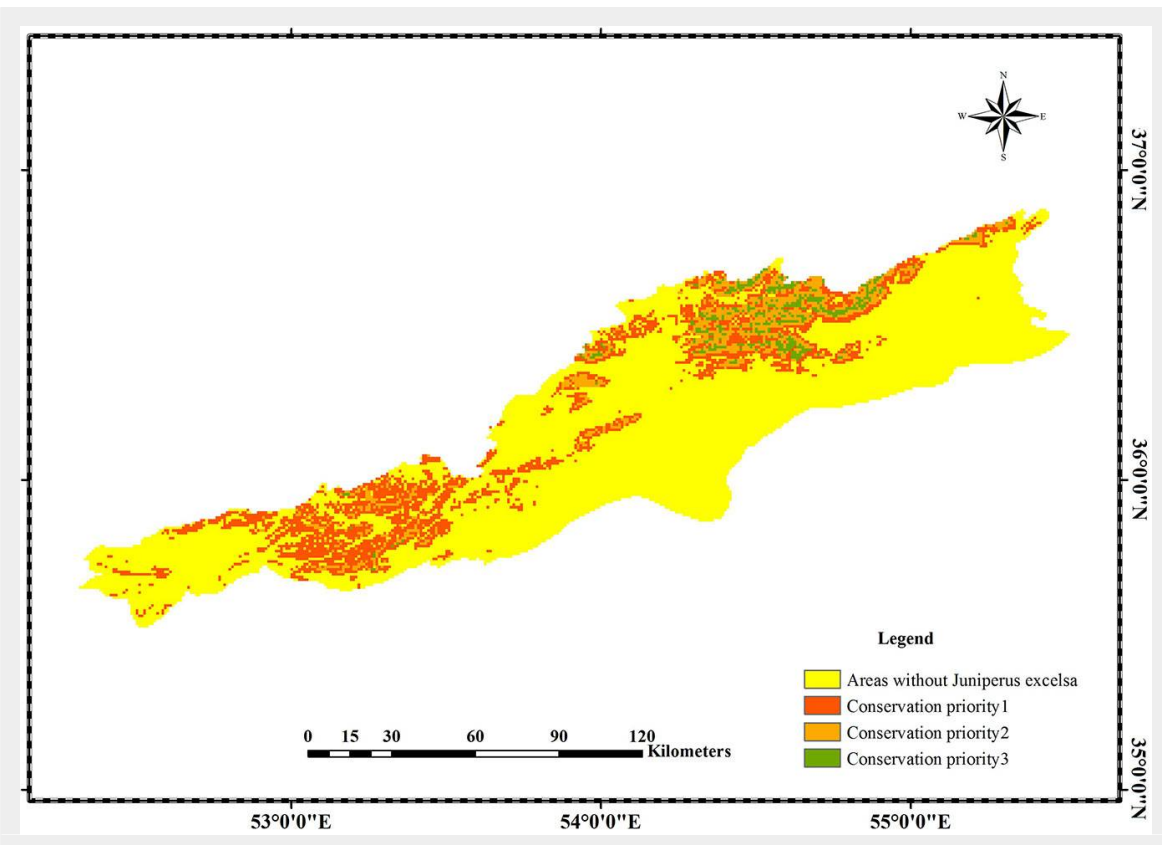

Fig. 6 - Conservation priority map for Juniperus excelsa in the study area.

rameters in the GFDL-CM3 and MRI-CGCM3 models.

The importance of J. excelsa as one of the characteristic tree species of the mountainous areas of Irano-Turanian region and its relevant role in soil conservation and preventing erosion and desertification necessitate proper planning for species' preservation on the southern slopes of Alborz Mountains. In view of this goal, a prioritization map was prepared (Fig. 6), where the study area was partitioned into three zones based on the likely climate change impact: (1) top priority zones, where the effects of climate change will work fastest; (2) moderate priority zones, where the effects of climate change will be moderate; (3) low priority zones, where the effects of climate change will likely be negligible.

Our results showed that GFDL-CM3 and MRI-CGCM3 data series both have a good performance in predicting the future habitat of J. excelsa in the study area (Pearson's correlation $=0.77$ ), but comparing the results with field conditions indicated that GFDL-CM3 is closer to the reality of the study area and its current trends (ignoring the unexpected events). This result is consistent with studies carried out in India (Remya et al. 2015) and in South and East Asia (Havlik et al. 2015), which examined the impact of climate change on developing countries with emphasis on the forestry sector, and also with the results of Mátyás (2010). The present study also demonstrated the good performance of MaxEnt model in evaluating the present and future distribution of J. excelsa, which agrees with Priti et al. (2016), who examined the effects of climate change on Myristicaceae species in East India, Choudhury et al. (2016) and Yu et al. (2014) who studied the preservation of natural reserves for endan- gered tree species in East China under the effects of climate change.

\section{Conclusions}

If the current trend of climate change continues, large parts of habitat of J. excelsa will be lost by 2070. This study focused on climatic parameters only, while ignored other factors such as human activities, management, and the occurrence of extreme events (floods and fires), which could also lead to a further shrinkage of suitable habitats for J. excelsa in northern Iran. In the IUCN Red List (IUCN 2016), J. excelsa is currently classified into the category of Least Concern, but the effects of increasing greenhouse gas emission as well as anthropogenic disturbance, its habitats are likely to face more serious threats in the next future. Our results can help in devising preservation strategies tailored to the expected changes in vegetation habitats under changing climatic conditions. To this regard, further studies are desirable, especially on endangered species and using other species distribution models, general circulation models, and scenarios.

\section{References}

Allouche O, Tsoar A, Kadmon R (2006). Assessing the accuracy of species distribution models: prevalence, kappa and the true skill statistic (TSS). Journal of Applied Ecology 43 (6): 12231232. - doi: 10.1111/j.1365-2664.2006.01214.x

Anderson RP, Lew D, Peterson AT (2003). Evaluating predictive models of species' distributions: criteria for selecting optimal models. Ecological Modelling 162: 211-232. - doi: 10.1016/S03 04-3800(02)00349-6

Anderson RP, Gonzalez JI (2011). Species-specific tuning increases robustness to sampling bias in models of species distributions: an implementation with Maxent. Ecological Modelling 222
(15): 2796-2811. - doi: 10.1016/j.ecolmodel.2011. 04.011

Araújo MB, Alagador D, Cabeza M, Nogués-Bravo D, Thuiller W (2011). Climate change threatens European conservation areas. Ecology letters 14 (5): 484-492. - doi: 10.1111/j.1461-0248.20 11.01610.x

Barbet-Massin M, Jiguet F, Albert CH, Thuiller W (2012). Selecting pseudo-absences for species distribution models: how, where and how many? Methods in Ecology and Evolution 3 (2): 327-338. - doi: 10.1111/j.2041-210X.2011.00172.x Bellard C, Bertelsmeier C, Leadley P, Thuiller W, Courchamp F (2012). Impacts of climate change on the future of biodiversity. Ecology letters 15: 365-377. - doi: 10.1111/j.1461-0248.2011.01736.x

Brzeziecki B, Kienast F, Wildi O (1995). Modeling potential impacts of climate change on the spatial distribution of zonal forest communities in Switzerland. Journal of Vegetation Science 6: 257-258. - doi: 10.2307/3236221

Choudhury MR, Deb P, Singha H, Chakdar B, Medhi M (2016). Predicting the probable distribution and threat of invasive Mimosa diplotricha Suavalle and Mikania micrantha Kunth in a protected tropical grassland. Ecological Engineering 97: 23-31. - doi: 10.1016/j.ecoleng.2016. 07.018

Elith J, Leathwick JR (2009). Species distribution models: ecological explanation and prediction across space and time. Annual Review of Ecology, Evolution and Systematics 40 (1): 677-697. - doi: 10.1146/annurev.ecolsys.110308.120159

Elith J, Graham CH, Anderson RP, Dudik M, Ferrier S, Guisan A, Hijmans RJ, Huettmann F, Leathwick JR, Lehmann A, Li J, Lohmann LG, Loiselle BA, Manion G, Moritz C, Nakamura M, Nakazawa Y, McOverton JC, Peterson AT, Phillips SJ, Richardson KS, Scachetti-Pereira R, Schapire RE, Soberon J, Williams S, Wisz MS, Zimmermann NE (2006). Novel methods improve prediction of species distributions from occurrence data. Ecography 29: 129-151. - doi: 10.1111/j.2006.0906-7590.04596.x

Elith J, Phillips SJ, Hastie T, Dudik M, Chee YE, Yates CJ (2011). A statistical explanation of MaxEnt for ecologists. Diversity and Distributions 17: 43-57. - doi: 10.1111/j.1472-4642.2010.007 25.x

Fallah A, Balapour Sh Yekekhani M, Jalilvand H (2014). Dendrochronological studies of Juniperus polycarpos in Alborz Mountains (case study: Shahkuh of shahrood). Iranian Journal of Wood and Paper Science Research 29 (1): 94-105. [online] URL: http://www.sid.ir/En/Journal/ViewPa per.aspx?ID=419267

Ferrarini A, Rossi G, Mondoni A, Orsenigo S (2014). Prediction of climate warming impacts on plant species could be more complex than expected. Evidence from a case study in the $\mathrm{Hi}$ malaya. Ecological Complexity 20: 307-314. - doi: 10.1016/j.ecocom.2014.02.003

Fischer HS (1990). Simulating the distribution of plant communities in an alpine landscape. Coenoses 5: 37-43. [online] URL: http://www. jstor.org/stable/43461021

Franklin J (2010). Mapping species distributions: spatial inference and prediction. Cambridge University Press, Cambridge, UK, pp. 319. [online] URL: http://books.google.com/books?id= CkshAwAAQBAJ 
Frey W, Probst W (1986). A synopsis of the vegetation in Iran. In: "Contributions to the Vegetation of Southwest Asia”. Ludwig Reichert Verlag, Wiesbaden, Germany, pp. 9-43.

Graham CH, Elith J, Hijmans RJ, Guisan A, Townsend Peterson A, Loiselle BA, The NCEAS Predicting Species Distributions Working Group (2008). The influence of spatial errors in species occurrence data used in distribution models. Journal of Applied Ecology 45: 239-247. doi: 10.1111/j.1365-2664.2007.01408.x

Guisan A, Theurillat JP (2000). Equilibrium modelling of alpine plant distribution and climate change: how far can we go? Phytocoenologia 30: 353-384. - doi: 10.1127/phyto/30/2000/353 Guisan A, Zimmermann NE (2000). Predictive habitat distribution models in ecology. Ecological Modelling 135: 147-186. - doi: 10.1016/S03043800(00)00354-9

Guisan A, Edwards TC, Hastie T (2002). Generalized linear and generalized additive models in studies of species distributions: setting the scene. Ecological Modelling 157: 89-100. - doi: 10.1016/S0304-3800(02)00204-1

Hall JB (1984). Juniperus excelsa in Africa: a biogeographical study of an Afromontane tree. Journal of Biogeography 11 (1): 47-61. - doi: $10.2307 / 2844775$

Havlik $P$, Valin $H$, Gusti $M$, Schmid $E$, Leclère $D$, Forsell N, Herrero M, Khabarov N, Mosnier A, Cantele M, Obersteiner M (2015). Climate change impacts and mitigation in the developing world. An integrated assessment of the agriculture and forestry sectors. World Bank Group, Washington, DC, USA, pp. 56. - [online] URL: http://elibrary.worldbank.org/doi/abs/10.1 596/1813-9450-7477

Hijmans RJ, Cameron SE, Parra JL, Jones PG, Jarvis A (2005). Very high resolution interpolated climate surfaces for global land areas. International Journal of Climatology 25 (15): 1965 1978. - doi: 10.1002/joc.1276

Hirzel AH, Hausser J, Chessel D, Perrin N (2002). Ecological-niche factor analysis: how to compute habitat suitability maps without absence data. Ecology 83: 2027-2036. - doi: 10.1890/00129658(2002)083[2027:ENFAHT]2.0.CO;2

IUCN (2016). The IUCN red list of threatened species (ver. 2016-2). Web site. [online] URL: http://www.iucnredlist.org

Khanum R, Mumtaz AS, Kumar S (2013). Predicting impacts of climate change on medicinal asclepiads of Pakistan using Maxent modeling. Acta Oecologica 49: 23-31. - doi: 10.1016/j.actao. 2013.02.007

Lehmann A, Overton JM, Leathwick JR (2002). GRASP: generalized regression analysis and spatial predictions. Ecological Modelling 157: 187-205. - doi: 10.1016/S0304-3800(02)00195-3

Li G, Xu G, Guo K, Du S (2016). Geographical boundary and climatic analysis of Pinus tabulaeformis in China: insights on its afforestation. Ecological Engineering 86: 75-84. - doi: 10.1016/ j.ecoleng.2015.10.032

Miller JA, Rogan J (2007). Using GIS and remote sensing for ecological modeling and monitor- ing. In: "Integration of GIS and remote sensing” (Mesev $\mathrm{V}$ ed). John Wiley and Sons Ltd, UK, pp. 233-268. [online] URL: http://www.re searchgate.net/publication/242577367

Miller J (2010). Species distribution modeling. Geography Compass 4/6: 490-509. - doi: 10.1111/ j.1749-8198.2010.00351.x

Mori AS, Spies TA, Sudmeier-Rieux K, Rade A (2013). Reframing ecosystem management in the era of climate change: issues and knowledge from forests. Biological Conservation 165: 115-127. - doi: 10.1016/j.biocon.2013.05.020

Mátyás C (2010). Forests and climate change in Eastern Europe and Central Asia. Forests and Climate Change Working Paper no. 8, Food and Agriculture Organization of the United Nations, Rome, Italy, pp. 189. [online] URL: http://www. environmentportal.in/files/eeca-recovered.pdf Munoz J, Felicisimo AM (2004). A comparison between some statistical methods commonly used in predictive modeling. Journal of Vegetation Science 15: 285-292. - doi: 10.1111/j.1654-11 03.2004.tbo2263.x

Parra JL, Graham CC, Freile JF (2004). Evaluating alternative data sets for ecological niche models of birds in the Andes. Ecography 27: 350360. - doi: 10.1111/j.0906-7590.2004.03822.x

Phillips SJ, Anderson RP, Schapire RE (2006). Maximum entropy modeling of species geographic distributions. Ecological Modelling 190: 231-259. - doi: 10.1016/j.ecolmodel.2005.03.026 Pourtahmasi K, Parsapajouh D, Marvi Mohajer M, Ali-Ahmad-Korouri S (2008). Evaluation of Juniper trees (Juniperus polycarpos C. Koch) radial growth in three sites of Iran by using dendrochronology. Iranian Journal of Forest and Poplar Research 16 (2): 342-347.

Priti H, Aravind NA, Shaanker RU, Ravikanth G (2016). Modeling impacts of future climate on the distribution of Myristicaceae species in the Western Ghats, India. Ecological Engineering 89: 14-23. - doi: 10.1016/j.ecoleng.2016.01.006 Ravanbakhsh H, Moshki A (2016). The influence of environmental variables on distribution patterns of Irano-Turanian forests in Alborz Mountains, Iran. Journal of Mountain Science 13 (8): 1375-1386. - doi: 10.1007/s11629-015-3789-y

Ravanbakhsh H, MarvieMohajer MR, Asadi M, Zobeiri M, Etemad V (2013). Classification of Juniperus excelsa $M$. Bieb forests vegetation and its analysis of relationship with environmental variables. Forest and Wood Product (Iranian Journal of Natural Resources) 66 (3): 277-292.

Ravanbakhsh H, Hamzehee B, Etemad V, Marvie Mohajer MR, Assadi M (2016). Phytosociology of Juniperus excelsa M. Bieb. forests in Alborz mountain range in the north of Iran. Plant Biosystems 150 (5): 987-1000. - doi: 10.1080/112635 04.2014.1000420

Remya K, Ramachandran A, Jayakumar S (2015). Predicting the current and future suitable habitat distribution of Myristica dactyloides Gaertn. using MaxEnt model in the Eastern Ghats, India. Ecological Engineering 82: 184-188. - doi: 10.1016/j.ecoleng.2015.04.053

Sagheb-Talebi K, Sajedi T, Pourhashemi M (2014).
Irano-Turanian region in forests of Iran. In: "Forests of Iran: A Treasure from the Past, a Hope for the Future". Springer Science and Business Media, Netherlands, pp. 67-113.

Sarangzai AM, Ahmed M, Ahmed A, Tareen L, Jan SU (2012). The ecology and dynamics of Juniperus excelsa forest in Balochistan-Pakistan. Pakistan Journal of Botany 44 (5): 1617-1625. [online] URL: http://www.researchgate.net/pu blication/232174166

Sass-Klaassen $U$, Leuschner $\mathrm{HH}$, Buerkert $\mathrm{A}$, Helle G (2007). Tree-ring analysis of Juniperus excelsa from the northern Oman Mountains. In: Proceedings of the "Dendrosymposium 2007", Riga (Latvia) 3-6 May 2007, pp. 99-108.

Segurado P, Araujo MB (2004). An evaluation of methods for modelling species distributions. Journal of Biogeography 31: 1555-1568. - doi: 10.1111/j.1365-2699.2004.01076.x

Tarkesh M, Jetschke G (2012). Comparison of six correlative models in predictive vegetation mapping on a local scale. Environmental and Ecological Statistics 19 (3): 437-457. - doi: 10.1007/s10651-012-0194-3

Warren R, Van Der Wal J, Price J, Welbergen JA, Atkinson I, Ramirez-Villegas J, Osborn TJ, Jarvis A, Shoo LP, Williams SE, Lowe J (2013). Quantifying the benefit of early climate change mitigation in avoiding biodiversity loss. Nature Climate Change 3 (7): 678-682. - doi: 10.1038/nclim ate1887

Yang XQ, Kushwaha SPS, Saran S, Xu J, Roy PS (2013). Maxent modeling for predicting the potential distribution of medicinal plant, Justicia adhatoda L. in lesser Himalayan foothills. Ecological Engineering 51: 83-87. - doi: 10.1016/j.ecol eng.2012.12.004

Yu J, Wang C, Wan J, Han S, Wang Q, Nie S (2014). A model-based method to evaluate the ability of nature reserves to protect endangered tree species in the context of climate change. Forest Ecology and Management 327: 48-54. - doi: 10.1016/j.foreco.2014.04.020

Yukimoto S, Adachi Y, Hosaka M, Sakami T, Yoshimura H, Hirabara M, Mizuta R (2012). A new global climate model of the Meteorological Research Institute: MRI-CGCM3 model description and basic performance. Journal of the Meteorological Society of Japan 90: 23-64. - doi: 10.2151/jmsj.2012-A02

Zohary M (1973). Geobotanical foundation of the Middle East. Taylor and Francis, UK, pp. 765.

\section{Supplementary Material}

\section{Fig. S1 - Climograph of study area.}

Fig. S2 - The response curves of environmental factors simulated by MaxEnt model.

Fig. S3 - Present and future climatic conditions and ecological response of Juniperus excelsa.

Link: Fatemi_2559@supploo1.pdf 